\title{
Monitoring of the Immune Response of Pregnant Ewes and their Offsprings Following the Vaccination of the Dams with Peste Des Petits Ruminants Attenuated Vaccine (75/1)
}

\author{
Hussein, A. H. M., Hanan M.S. El-Zawahry, Abeer A. Tammam \\ Veterinary Serum and Vaccine Research Institute, Abbasia, Cairo
}

\begin{abstract}
Assessment of the neutralizing antibody response to the attenuated strain of peste des petits ruminants Nigerian strain (75/1) in 5 pregnant ewes revealed a geometric mean titre of 194, four weeks post Vaccination. Such an appreciably high titre was found to be dropped to 73.5, throughout 48 hours post parturn. Suckling kids born to these dams passively acquired a titre of 84.5 throughout their first month of life that dropped to 48.5 at the age of 2 months. At their 5 th month of age their immune titre was found to be only 4. Data generated from this study might be of value in launching vaccination campaigns against peste des petits ruminants disease.
\end{abstract}

Peste des petits ruminants (PPR) (Gargadennec and Lalanne, 1942) and (Furley et al., 1987 ) is a viral disease of goats and sheep characterized by necrotizing and erosive stomatitis, enteritis and pneumonia. The causative agent is peste des petits ruminants virus (PPRV). It is a member of the family Paramyxoviridae and the genus Morbillivirus (Gibbs et al., 1979).

PPR has a very high rate of morbidity and mortality and the effective control of this disease is of economic importance in Africa, Asia and the Middle East (OlE, 2008). The disease is a fast spreading infection of small ruminants. It is characterized by sudden onset of depression, fever, discharges from the eyes and nose, sores in the mouth, disturbed breathing and cough, foul-smelling diarrhoea and death (OlE, 2008). Vaccination of small ruminants with the homologous PPR vaccine (Nigeria 75/1) produces high titres of PPR specific antibodies (Diallo et al., 1989; Couacy et al., 1995; Bidjeh et al., 1999; Martrenchar et al., 1999; Awa et al., 2002).

The vaccine is also safe for pregnant females (Couacy, 1994). The present study was aiming to monitor of the immune response of pregnant ewes and their offspring following vaccination of dams with the Nigerian attenuated PPR vaccine.

\section{Material and methods}

Animals.

Pregnant ewes. Six pregnant ewes proved to be seronegative to PPRV, through screening their serum samples for specific PPRV-neutralizing antibody, were used in the present study.
Screening of test animals was done using serum neutralization test (SNT) (Lefevre et al., 1991). Randomly selected five ewes of these animals were subjected each to a subcutaneous vaccination dose representing $3 \log _{10} \mathrm{TCID}_{50}$ at a late stage of pregnancy (50-60 days pre-partum) of PPRV-attenuated vaccine Nigerian strain (75/1) (OlE, 2008). The sixth ewe was held as an unvaccinated control one.

Kids. Six kids were born to the six ewes and were given their mothers' numbers. These kids as well as their nursing mothers were monitored for the existence of PPRV-neutralizing antibody through the application of SNT on serum samples collected at predetermined indicated intervals (Tables 1 and 2).

Virus. The attenuated strain of Nigerian PPRV $(75 / 1)$ was used to vaccinate 5 pregnant ewes with a subcutaneous dose of $3 \quad \log _{10}$ $\mathrm{TCID}_{50} /$ head. It was also used on carrying out SNT through a virus dilution of $100 \mathrm{TCID}_{50} / 0.1$ $\mathrm{ml}$ of virus suspension (OlE, 2000, 2004 and 2008).

Virus titration. Whenever needed, PPRV titration was carried out according to the method described by Anderson and McKay (1994).

Monitoring of the PPRV-neutralizing antibody response. This was carried out at predetermined indicated intervals (Tables 1 and 2) through the utilization of the SNT applied on serum samples collected from vaccinated ewes, as well as suckling kids.

\section{Results and discussion}

PPR is one of the most economically important animal diseases and severely impacts 
the lives and livelihoods of the world's poorest. However, prevention, control and vaccination tools exist (OlE, 2012).

Data obtained through the present study are illustrated in Tables (1 and 2), which obviate the seronegativity of the test pregnant ewes just prior to vaccination with the attenuated PPRV-vaccine Nigerian strain $(75 / 1)$. Such a seronegativity is considered a necessity contribution to the credibility of results of the study presented. The PPRV-vaccine dose of $3 \log _{10} \mathrm{TCID}_{50} /$ head of sheep given subcutaneously is acknowledged by concerned international organizations as a minimum efficient dose required to elicit a protective immune response (OlE, 1996, 2000, 2004 and 2008). The conception that a neutralizing antibody titre of 16 at least, to such a vaccine is quite protective against infection also approved (OlE, 1996, 2000, 2004 and 2008). The vaccinated five pregnant ewes remained healthy throughout the period of study. Their acquisition of a neutralizing antibody titre ranging between 32 and 128 with geometric mean titre of 64 , is for beyond the minimum essential value (16). This was found 3 weeks post vaccination of pregnant ewes. Maximum titres ranging between 128 and 256 with mean titre of 194 were found in vaccinated animals one week later (Tables 1 and 2). The $4^{\text {th }}$ week post vaccination maximum neutralizing antibody titre phenomenon was observed by several authors (Zaghawa et al., 1992; FAO, 1996; Nahed et al., 2000 and OlE, 2012). The result that such a high antibody titre level was in pregnant ewes found to be as low as 73.5 in lactating dams is of much interest. Such a result was correspondingly previously found by Lyigoren et al., (1976) and Zagliawa et al., (1992). However, their observation was in rinderpest-vaccination cattle. Suckling kids passively acquired a high neutralizing antibody titre, as a mean one of 84.4 throughout the period from 5 days up to one month of age. It is axiomatic to understand that ingestion of the colostrum plays an indispensable role in acquisition of such a high titre of antibodies (Tables 1 and 2). It is noteworthy to mention that a decline to the level of 48.5 was observed at the age of 2 months (Tables 1 and 2). Such a decline continued to occur till being as low as only 4 at the age of 5 months. In this respect, it is well known that the protection of offspring against many infectious agents during the first months of life depend on the maternally acquired immunity through the ingestion of colostrum. The duration of maternal antibodies influences the optimal age for vaccination. A similar study conducted on 11 lambs born to ewes vaccinated with the heterologous Rinderpest vaccine (Plowright and Ferris, 1962) has shown that the passive immunity protects lambs for more than 3 months. Nevertheless the authors recommended vaccination of lambs at 3 months of age against PPR (Ata et al., 1989). Bidgeh et al., (1999) suggested the vaccination of lambs and kids at 4 to 5 months of age. Another investigation on the duration of maternal antibodies specific to PPR in lamb and kid flocks demonstrated that they failed to be protected after 3.5 and 4.5 months in lambs and kids, respectively (Awa et al., 2002). Therefore, it was recommended to vaccinate them at 4 and 5 months of age, respectively.

The data generated from the present study suggest that the optimal age for the vaccination of lambs against PPR is from day 120 to day 150 after birth. Approximate findings were demonstrated by Awa et al., (2002), who suggested that kids and lambs from immunized or exposed dams should be vaccinated at 4 and 5 months of age respectively as far as PPR is concerned. It is noteworthy to mention that immunity can be produced through vaccination when the maternal antibodies recede to a low level in kids, whereas high levels of maternal antibodies would block the effectiveness of the vaccine. There is a window of susceptibility period from several days to weeks in which the maternal antibodies are too low to provide protection against the disease, but too high to allow a vaccine to work.

This study highlights clearly that 5 months after brith, 3 out of 5 lambs have lost their maternal antibodies; thus left without any protection.

It could be concluded that data generated from the present study would be of value in launching vaccination campaigns against PPR. 
Table (1): PPRV serum neutralizing antibody titers induced 6 goats the Nigerian attenuated strain of PPRV $(75 / 1)$ in pregnant ewes and their offsprings.

\begin{tabular}{llcccccc}
\hline Animals & Sampling chronology & $\mathbf{1}^{*}$ & $\mathbf{2}$ & $\mathbf{3}$ & $\mathbf{4}$ & $\mathbf{5}$ & $\mathbf{6}^{* * *}$ \\
\hline \multirow{2}{*}{ Pregnant } & Just prior to vaccination & $0^{* *}$ & 0 & 0 & 0 & 0 & 0 \\
ewes & 3 weeks post vaccination & 64 & 128 & 128 & 32 & 32 & 0 \\
& 4 weeks post vaccination & 128 & 256 & 256 & 128 & 256 & 0 \\
\hline \multirow{4}{*}{ Dams } & 2 hours post partum & 32 & 64 & 128 & 64 & 128 & 0 \\
& 7 hours post partum & 32 & 64 & 128 & 64 & 128 & 0 \\
& 24 hours post partum & 32 & 64 & 128 & 64 & 128 & 0 \\
& 48 hours post partum & 32 & 64 & 128 & 64 & 128 & 0 \\
\hline \multirow{5}{*}{ Offsprings } & Just prior to suckling & 0 & 0 & 0 & 0 & 0 & 0 \\
& 5 days old & 64 & 128 & 128 & 64 & 64 & 0 \\
& 10 days old & 64 & 128 & 128 & 64 & 64 & 0 \\
& 15 days old & 64 & 128 & 128 & 64 & 64 & 0 \\
& 30 days old & 64 & 128 & 128 & 64 & 64 & 0 \\
& 60 days old & 32 & 64 & 128 & 32 & 32 & 0 \\
& 90 days old & 16 & 64 & 128 & 16 & 16 & 0 \\
& 150 days old & 0 & 16 & 16 & 4 & 0 & 0 \\
\hline
\end{tabular}

\section{* Animal numbers}

** PPRV-neutralizing antibody titres expressed as the reciprocal of the final dilution of serum inhibiting the CPE produced by $100 \mathrm{TCID}_{50} / 0.1$. $\mathrm{ml}$ of PPRV on Vero cells

*** Unvaccinated control animals.

Table (2): PPRV-Gcometric mean of serum neutralizing antibody titers induced by the Nigerian attenuated strain of PPRV (75/1) in pregnant ewes, and their offsprings.

\begin{tabular}{clcc}
\hline Test of & Sampling chronology & $\begin{array}{c}\text { * Geometric mean of } \\
\boldsymbol{P P R} \text { seurm neutralizing } \\
\text { antibody titres }\end{array}$ & $\begin{array}{c}\text { Unvaccinated control } \\
\text { animals }\end{array}$ \\
\hline \multirow{2}{*}{$\begin{array}{c}\text { Pregnant } \\
\text { ewes }\end{array}$} & Just prior to vaccination & 1 & 0 \\
& 3 weeks post vaccination & 64 & 0 \\
\hline \multirow{2}{*}{ Dams } & 4 weeks post vaccination & 194 & 0 \\
& 2 hours post partum & 73.5 & 0 \\
& 7 hours post partum & 73.5 & 0 \\
& 24 hours post partum & 73.5 & 0 \\
\hline \multirow{2}{*}{ Offsprings } & 48 hours post partum & 73.5 & 0 \\
& Just prior to suckling & 84.4 & 0 \\
& 5 days old & 84.4 & 0 \\
& 10 days old & 84.4 & 0 \\
& 15 days old & 84.4 & 0 \\
& 60 days old & 48.5 & 0 \\
& 90 days old & 32 & 0 \\
\hline
\end{tabular}

* Geometric mean of PPR serum neutralizing antibody titers of five animals represented as the reciprocal of the final dilution of serum inhibiting the CPE produced by $100 \mathrm{TCTD}_{50} \mathrm{ml}$ of PPRV on Vero cells.

\section{References}

Anderson, J. and Mckay, J.A. (1994): The detection of antibodies against peste des petits ruminants virus in cattle, sheep and goats and the possible implication to Rinderpest control programmes. Epidem. Infect., 112: 225-234.

Ara, F.A.; AJ-Sumry, S.; King, G.J.J.; Ismaili, S.1. and Ata, A.A. (1989): Duration of maternal immunity to peste des petits ruminants. Vet. Rec., 124: 590-591.

Awa, D.N.; Nagagnon, A.; Tefiang, E.; Yaye, D. and Njoya, A. (2002): Post vaccination and colostral peste des petits ruminants antibody dynamics in research flocks of
Kirdi goats and Foulbe sheep of north Cameron. Preventive Vet. Med., 55: 265-271.

Bidjch, K.; Diguimbayc, C.; Tehari, B. and Naissingar, S. (1999): Immuite passive colostrate chez les jeunes issue des cheves et brebis vaccine's avec les vaccin anti-peste des petits ruminants. Cahier Agricole, 8L2 19-222.

Couacy-Hymann, E. (1994): La lutte contre Ia peste bovine en Cote d'Jvoire. Couts et benefices des compagnes de prophylaxie. Problemes poses pour son eradication. These de Doctorat es Sceince, Vol. 1.25 ip.

Conacy-Hyman, ED.; Bidjeb, K.; Angba, A.; Domenech, 
S. And Diallo, A. (1995): Protection of goats against Rinderpest by vaccination with attenuated peste des petits ruminants virus. Rec. Vet. Sci., 59: 106- 109.

Diallo, A.; TayJor, W.P.; Lefewre, P.C. and Provost, A. (1989): Attenuation of a virulent PPRV strain: Potential homologous live vaccine. Rev. Elev. Med. Pays Top., 42(3): 311-319.

FAO (Food and Agriculture Organization) (1996): Recognizing peste des petits ruminants, 1-15.

Furley, C.W.; Taylor, W.P. and Obi, T.U. (1987): An outbreak of peste des petits ruminants in a zoological collection. Vet. Rec., 121 (9): 443-447.

Gargadennec, L. and Lalanne, A. (1942): La peste des petits ruminants (An undiagnosed transmissible disease of goats and sheep. Bull. Serv. Zootech. Epiz. A.O.F.S.: 16-2 1.

Gibbs, E.P.J.; Taylor, W.P.; Lawman, M.J.P. and Bryant, J. (1979): Classification of peste des petits ruminants virus as the fourth number of the genus
Morbillivirus. Intervirology, 11: 268-274.

Lefewre, P.C.; Diallo, A.; Schenkel, F.; Hllssein, S. and Staak, C. (1991): Serological evidence of peste des petits ruminants in Jordan. Vet. Rec., 128: 110.

Lyigoren, 0.; Unlu, M. and Youngus, A.O. (1976): Studies on the pre and post partum serum antibodies in cows vaccinated against rinderpest. Et. Vet. Bak. Enst. Der., 4: 59-7 1.

Martrenchar, A.; Zoyem, N.; Njoya, A.; Ngotama, A.C.; Bouchel, D. and Diallo, A. (1999): Field study of a homologous vaccine against peste des petits ruminants in northern Cameron. Small Rumin. Res., 31: 277-280.

Nahed. A.K.; Hussein, A.H.M.; Samia, A.A. Ayad and Mouaz, M.A. (2000): Response of pregnant sheep and goats to a specific vaccine for peste of small ruminants. Vet. Med., Giza, Vol. 48, No. A: 617- 614.

OIE (1996): OIE International Committee Report of the 66th General Session. Paris, 25-29 May, 1996, P.S. Animal Disease Status World Wide in 1997. 